\title{
ISOLAMENTO HOSPITALAR PEDIÁTRICO: práticas e recursos na perspectiva da psicologia
}

DOI: $10.22289 / 2446-922 X . V 7 N 1 A 28$

\author{
Stéfany Bruna de Brito Pimenta ${ }^{1}$ \\ Sandra de Fátima Barboza Ferreira \\ Ana Idalina de Paiva Silva
}

\section{RESUMO}

O objetivo do trabalho é identificar práticas implementadas no isolamento hospitalar pediátrico com vistas a diminuir o sofrimento psíquico. Trata-se de um estudo qualitativo, exploratório e descritivo. Adotou-se a metodologia de triangulação de fontes: levantamento bibliográfico (BVS-BIREME, PubMed, Google acadêmico e PsycINFO); entrevistas abertas com profissionais experientes de serviços pediátricos hospitalares e busca web de técnicas para humanização no contexto do isolamento hospitalar. Os resultados indicaram escassez de literatura especializada, predominância de estudos qualitativos e tendência a valorizar recursos materiais em detrimento de recursos relacionais, bem como existência de práticas carentes de maior evidência científica. $A$ adoção dessas práticas depende de fatores relacionados à letalidade do agente patógeno, à idade e ao interesse da criança, do nível de responsividade, do acesso a recursos materiais e a flexibilidade da equipe de saúde em ponderar sobre riscos/benefícios, ensejando práticas idiossincráticas.

Palavras-chave: Isolamento de Pacientes; Criança Hospitalizada; Pediatria.

\section{ISOLATION FOR PEDIATRIC PATIENTS: practices and resources from the perspective of psychology}

\section{ABSTRACT}

The work's aim is to identify practices implemented in hospital pediatric isolation in order to reduce psyhcic suffering. It is a qualitative, exploratory and descriptive study. A source triangulation methodology was used: (BVS-BIREME, PubMed, Google acadêmico and PsycINFO) open interviews with experienced professionals who were active in pediatric hospital services was done; and, an online search was done on techniques to humanize pediatric hospital isolation services. The results indicated scarcity of specialized literature, predominance of qualitative studies and tendency to value resources over relational resources, as well as the existence of practices lacking more scientific evidence. The employment of these practices depends on factors related to the lethality of the pathogen, the child's age and concernment, the responsivity level, the access to material resources and the health team's flexibility in regard to pondering about risks/benefits, experimenting with idiosyncratic practices.

Keywords: Patient Isolation; Hospitalized children; Pediatric.

\footnotetext{
${ }^{1}$ Endereço eletrônico de contato: stefanybbp@homail.com

Recebido em 02/02/2021. Aprovado pelo conselho editorial para publicação em 22/06/2021.
} 


\section{EL AISLAMIENTO HOSPITALARIO PEDIÁTRICO: prácticas y recursos para reducir a angustia psicológica}

\section{RESUMEN}

El objetivo del trabajo es identificar las prácticas implementadas en el aislamiento hospitalario pediátrico para reducir la angustia psicológica. Se trata de un estudio cualitativo, exploratorio y descriptivo. La metodología adoptada fue la de triangulación de origen: primero, se realizó un estudio en bases de datos científicas (BVS-BIREME, PubMed, Google acadêmico y PsycINFO); entrevistas abiertas con profesionales experimentados enatención pediátrica hospitalaria; una búsqueda en la web de técnicas de humanización en el contexto del aislamiento hospitalario. Los resultados indicaron escasez de literatura especializada, predominio de estudios cualitativos y tendencia a valorar los recursos materiales en detrimento de los recursos relacionales, así como la existencia de prácticas que carecen de mayor evidencia científica. La adopción de esas prácticas depende de factores relacionados con la letalidad del agente patógeno, la edad y el interés del niño, del nivel de responsividad, del acceso a los recursos materiales y la flexibilidad del equipo de salud al evaluar riesgos/beneficios, posibilitando prácticas idiosincrásicas.

Palabras clave: Aislamiento de Pacientes; Niños Hospitalizados; Pediatría.

\section{INTRODUÇÃO}

Isolamento hospitalar é a medida que visa segregar pessoas infectadas, durante o período de transmissibilidade de um agente patógeno, em local com condições para evitar a contaminação direta ou indireta (Nichiataet al., 2004; World Health Organization - WHO, 2016). Ele também pode ser utilizado quando há condições de imunossupressão do paciente, na tentativa de evitar ao máximo contaminação cruzada no hospital (Alvarez, Pike \& Goldwin, 2019).

O isolamento de pessoas com doenças infectocontagiosas como medida sanitária é relatado desde o século XIV e o isolamento em ambiente hospitalar é praticado desde o século XIX. Nichiata e colaboradores (2004) apresentaram a evolução histórica e as diferentes concepções que emergiram acerca dessa intervenção, e mostraram o quanto essa prática vem se tornando cada vez mais protocolar com vistas a garantir os cuidados básicos de saúde dos pacientes.

A produção científica existente a respeito da clínica do isolamento é de natureza biomédica, com destaque para artigos predominantemente produzidos por profissionais da área médica e de enfermagem (Campbell \& Crews, 2019). A abordagem biomédica enfatiza os cuidados da equipe de saúde em relação às doenças infectocontagiosas, abordando os riscos de contaminação, sobretudo pelos profissionais de saúde. Em sua maioria, os trabalhos ressaltam a importância e necessidade de se seguir adequadamente as medidas de precaução, pontuando a necessidade da adesão de toda equipe para o efetivo controle das infecções e o manejo correto da assistência 
(Carvalho \& Marques, 1999; Nichiata et al., 2004; Brasil, 2006; Yamamura et al.,2011; McNeil, Campbell \& Crews, 2019).

Essas produções abordam que a precaução padrão é necessária e deve ser adotada como um protocolo que reduz os riscos de transmissão de micro-organismos através de secreções e fluidos corporais. Esses protocolos preveem procedimentos hospitalares, tais como o uso de equipamentos de proteção individual (EPIs), como: luvas, aventais e/ou máscaras, bem como a constante lavagem das mãos antes e após a manipulação dos pacientes (Brasil, 2006; World Health Organization - WHO, 2016; McNeil, Campbell \& Crews, 2019).Por outro lado, o isolamento hospitalar é uma forma de prevenção complementar específica diante das patologias infectocontagiosas, considerando as seguintes formas de transmissão (Brasil, 2000; Nichiata et al., 2004; WHO, 2016; Committee on Infectious Diseases, American Academy of Pediatrics - CIDAAP, 2018):

A) Por meio do contato: o mais frequente e importante meio de transmissão de infecções hospitalares. Pode ocorrer através das mãos dos profissionais; das luvas quando não trocadas entre um paciente e outro; pelo contato entre pacientes e de instrumentos contaminados;

B) Através de gotículas: tosse, espirro, aspiração de secreções, realização de procedimentos (como broncoscopia) e mesmo pela conversação habitual. Quando estas partículas são depositadas na conjuntiva, mucosa nasal ou na boca do hospedeiro susceptível, ocorre a transmissão do agente. As partículas podem atingir uma distância de um metro. Essa forma de transmissão não é aérea porque as gotículas não permanecem suspensas no ar;

C) Por aerossóis: a transmissão aérea ocorre quando os microrganismos estão em pequenas partículas suspensas no ar $(=5 \mu \mathrm{m})$ ou gotículas evaporadas que permanecem suspensas no ar por longo tempo. Os microrganismos carreados desta forma são disseminados por correntes de ar e podem ser inalados por hospedeiros susceptíveis, mesmo a longas distâncias.

D) Por veículo comum: ocorre quando os microrganismos são transmitidos por veículo comum como alimentos, água, medicamentos ou mesmo equipamentos.

E) Por vetores: ocorre quando vetores como moscas ou mosquitos transmitem microrganismos.

A transmissão dependerá também da susceptibilidade do paciente à infecção, sendo as crianças e idosos mais vulneráveis. Em pediatria as infecções hospitalares merecem atenção especial. Quando adquiridas complicam o tratamento da criança, aumentando a morbidade, mortalidade, o tempo de permanência no hospital e, consequentemente, o sofrimento da criança e de sua família (Rabelo \& Souza, 2009).

Diante do exposto, verifica-se que o isolamento hospitalar é uma medida preventiva importante e necessária ao tratamento de diferentes pacientes. Contudo, é preciso um olhar holístico sobre a saúde destes. Estudos reforçam que tanto o fenômeno do adoecer, quanto a 
terapêutica do isolamento trazem repercussões significativas para a vida dos sujeitos, afetando-os não apenas em seus aspectos biológicos, mas também emocionais e sociais (Chiattone, 2009; Mori \& Rey, 2012, Depianti, Melo e Ribeiro, 2018 e Ferreira et al 2019). Portanto, ainda que predomine as pesquisas de natureza biomédica, faz-se necessário a sistematização de estudos que abordem o fenômeno do isolamento hospitalar pediátrico em seu aspecto psicossocial, sendo frequentemente demandado ao psicólogo hospitalar que ele proveja a equipe de orientações e técnicas para mitigar o sofrimento psíquico nessa circunstância.

\section{DESENVOLVIMENTO}

No campo da psicologia é possível encontrar estudos enfocando os efeitos deletérios do distanciamento social e afetivo sobre o desenvolvimento infantil há quase um século. No entanto, poucos estudos são encontrados no âmbito específico da psicologia hospitalar, o que foi modificado pela pandemia da COVID-19 (Melo et al., 2020), quando essa temática ganhou interesse coletivo.

\section{Consequências psíquicas do isolamento em crianças}

De acordo com a revisão de Abad, Fearday e Safdar (2010), o isolamento hospitalar pediátrico provoca efeitos deletérios sobre a saúde mental e afeta diretamente o desenvolvimento psicológico das crianças. Da mesma maneira, René Spitz já havia observado o que nomeou "hospitalismo" em 1945, que seriam níveis de depressão exacerbados em crianças que viveram situações de abandono e isolamento em instituições (Spitz,1945). O autor defende que a falta de afeto seria a principal causa desse fenômeno.

Spitz (1991) e Bowlby (1979/1997) realizaram estudos e experimentos que corroboram a tese da importância das relações objetais afetivas para a criança e de seu vínculo com a mãe. Ao analisar a carência afetiva do bebê, Spitz (1991) considerou os casos em que há ausência física da mãe e um substituto inadequado ou inexistente, como pode ocorrer no caso da hospitalização. Ele distinguiu a privação afetiva parcial e total, considerando que o dano sofrido pela criança será proporcional à duração da privação. Para o autor, a privação total de afeto por mais de cinco meses no primeiro ano de vida da criança gera sintomas de progressiva deterioração que são aparentemente irreversíveis. Em sua visão, não seria a institucionalização da criança em si a causa dos danos ao seu desenvolvimento, mas os fatores específicos dessa instituição.

Bowlby (1979/1997) conceitua como o cerne do vínculo afetivo a atração que um indivíduo sente por outro, ressaltando que o primeiro e mais persistente de todos os vínculos é geralmente entre a mãe e o filho. Sendo a característica principal da vinculação afetiva a busca para se manter próximo, as tentativas de separação de um par vinculado serão atacadas com resistência, pois os 
vínculos afetivos são acompanhados por estados subjetivos de fortes emoções. Bowlby (1979/1997, p. 98) ressalta que "muitas das intensas emoções humanas surgem durante a formação, manutenção, rompimento e renovação de vínculos emocionais". Para ele uma criança pequena que se vê entre estranhos e sem as figuras parentais pode se mostrar aflita no momento e apresentar comprometimentos nas relações subsequentes, ainda que temporariamente.

Ao estudar os prejuízos do desamor, Bowlby (1985/2004) contrasta crianças que tiveram uma permanência no hospital com acompanhantes a outro grupo que permaneceu sem acompanhantes. O autor identifica que neste último grupo há uma perturbação no vínculo, sendo que essas crianças apresentaram mais comportamentos de dependência ou desligamento emocional. Para ele, os fatores que atenuam as reações das crianças à separação da mãe são os cuidados de uma substituta e a presença de pessoas ou objetos conhecidos.

Embora criticados por superestimar o papel da figura materna no desenvolvimento psicológico da criança (Rowold, 2018), esses estudos sobre os vínculos da criança ainda têm grande prestígio no campo da saúde mental e do desenvolvimento psicológico e, seguramente, embasam práticas de humanização dos serviços, garantindo a presença de um cuidador e, quando isso não é possível, prevê a posse de um objeto ou brinquedo de valor afetivo, como teoriza Winnicott (1975) acerca dos objetos transicionais.

\section{Isolamento hospitalar pediátrico}

A adoção das medidas de isolamento para crianças, inclusive de seus cuidadores, tem dividido comitês de controle de infecção hospitalar $(\mathrm{CCIH})$ e profissionais de saúde acerca das contradições entre cumprir um protocolo seguro de proteção e ofertar, ao mesmo tempo, uma assistência humanizada ao paciente, quando se trata de paciente de tenra idade, mesmo levandose em conta situações em que o agente patógeno apresenta altíssima letalidade.

O isolamento hospitalar pediátrico é uma medida de proteção para a criança ante os fatores externos de contaminação durante o período de antibioticoterapia e reduz os riscos de infecção cruzada. Ocorre em um quarto privativo, sendo que os itens e superfícies ambientais em contato com o paciente devem ser submetidos à limpeza diária. Todos os artigos e equipamentos deverão ser de uso exclusivo para cada paciente e, caso o material (talheres, brinquedos etc.) não seja descartável, deverá ser rigorosamente desinfectado. Deste modo, o contato com pessoas e objetos é fortemente restringido (Brasil, 2000; CIDAAP, 2018; Miranda, 2019).

Neste ambiente restritivo as necessidades emocionais da criança aumentam significativamente (Chiattone, 2009; Miranda, 2019). No isolamento, a criança não está separada apenas das pessoas que ama e dos ambientes que anteriormente convivia, mas se isola também da própria convivência dentro do hospital. Seus movimentos são limitados e há redução dos 
estímulos externos. Crianças internadas podem passear pela área externa do hospital, por exemplo, mas as que permanecem no isolamento estão privadas desta possibilidade. Chiattone (2009) afirma que se a doença e a hospitalização em si podem gerar culpa e alguma sensação de abandono na criança, o isolamento parece confirmar tal situação.

$\mathrm{O}$ adoecer possui uma realidade tanto objetiva quanto subjetiva e intersubjetiva. A vivência é sentida no corpo, nas sensações e emoções individuais, mas também se relaciona com representações sociais (valores, crenças, expectativas). Portanto, no caso das doenças infectocontagiosas, a criança pode sentir os impactos em seu corpo fragilizado, em suas vivências pessoais e em suas relações com os outros, agora limitadas (Mori \& Rey, 2012).

A ansiedade gerada tanto na criança quanto em seu cuidador está ligada não só à barreira física e social que lhes é imposta, mas também pelas complicações próprias da doença infecciosa (Cardim et al., 2008; Melo et al, 2020). Algumas doenças são acompanhadas de marcas no corpo, além de estigmas e mitos sociais. Algumas podem causar odores, coceiras, tosses incontroláveis e secreções incômodas, fragilizando ainda mais o estado físico e emocional do paciente e seus familiares. A percepção de estar contaminado ou de lidar com alguém que pode vir a se contaminar mobiliza a relação da criança com seu cuidador, e destes com a equipe, gerando receios que contribuem para o aumento do sofrimento.

É fundamental compreender a mudança ambiental e psicossocial que é imposta à criança, tendo sensibilidade para apreender as implicações destas alterações para o paciente. Olhar para a mesma em isolamento hospitalar não só em seus aspectos biológicos, mas também afetivos e sociais é resgatar a concepção de sujeito integral no contexto da saúde. Compreender suas necessidades durante o isolamento implica também no exame das relações sociais que ela tem neste ambiente, sendo de destaque a relação com seu acompanhante.

De um modo bastante específico, a situação de isolamento hospitalar impõe restrições que podem comprometer as necessidades psicossociais dos pacientes. As especificidades do funcionamento na unidade de isolamento hospitalar geram uma rotina diferenciada para o paciente e o cuidador durante a internação, bem como atendimentos profissionais diferentes dos que são feitos tradicionalmente nos demais leitos da enfermaria.

Assim, é fundamental a compreensão do fenômeno do isolamento hospitalar abordando também os fatores psicossociais que estão envolvidos nesse processo. A consideração deste fenômeno em sua integralidade, ou seja, em suas implicações biológicas e psicossociais fornece subsídio para o desenvolvimento de protocolos de intervenção mais efetivos e eficazes, contribuindo para a promoção da saúde em seu sentido amplo. 


\section{Objetivo e Justificativa}

Este trabalho tem como objetivo identificar práticas e recursos que podem ser implementados no isolamento hospitalar pediátrico, provendo recomendações aos profissionais e garantindo uma intervenção mais humanizada aos pacientes.

Tendo em vista que o quadro de restrição do isolamento hospitalar pode potencializar o sofrimento vivenciado pela criança (Parcianello \& Felin, 2008), espera-se dos profissionais de saúde, além da assistência biomédica, o desenvolvimento de técnicas e manejos terapêuticos que amenizem os impactos deletérios do isolamento hospitalar e promovam maior bem-estar psicossocial de seus pacientes.

O enfoque exclusivo no fator biológico do tratamento das doenças infectocontagiosas pode suscitar práticas tecnicistas. As pesquisas no campo têm refletido tal problemática na medida em que grande parte das produções focaliza a prevenção da transmissão e não necessariamente o cuidado aos sujeitos em isolamento (Cardim et al., 2008). Por sua vez, o Manual de Prevenção e Controle da Pediatria (Brasil, 2006) pontua que o isolamento propõe um desafio maior nas práticas de humanização pelos profissionais de saúde, no reconhecimento dos direitos da criança, suas necessidades, processos de desenvolvimento e sua subjetividade como um todo.

\section{Método}

O estudo é exploratório, descritivo, qualitativo, e propõe a metodologia de triangulação de fontes de dados para análise de seus resultados.

De acordo com Santos e colaboradores (2020), a triangulação favorece a análise de diversas perspectivas de compreensão dos fenômenos em um único método. Esta metodologia tem sido amplamente utilizada no âmbito das ciências da saúde no intuito de apreender a complexidade da realidade por duas ou mais abordagens metodológicas (Nierotka, Monteiro, \& Silva, 2020). A triangulação pode ser aplicada de cinco maneiras: a triangulação de fontes de dados, de investigador, de métodos, de teorias ou ambiental, o que permite o acesso a diferentes níveis de profundidade que o desvelamento de um fenômeno complexo exige (Santos et al., 2020). Neste trabalho, realizou-se a triangulação de fontes de dados.

As fontes de dados utilizadas para triangulação foram: pesquisa bibliográfica, entrevistas com profissionais e busca web por recursos atualizados.

\section{Coleta dos dados.}

Rev. Psicol Saúde e Debate. Jun., 2021:7(1): 408-429. 


\section{Pesquisa bibliográfica.}

Com o objetivo de identificar técnicas e procedimentos consagrados na literatura científica, foi realizado um levantamento bibliográfico em bases de dados científicas (Biblioteca Virtual de Saúde-BIREME, PubMed, PsycINFO e Google acadêmico) com os descritores: Patients Isolation; hospitalization; Isolation precaution e combinações de refinamento com child, children, pediatric and child*. Refinou-se a busca para aspectos psicológicos. Adotou-se como critério de elegibilidade apenas aqueles artigos completos que mencionassem claramente práticas, técnicas e/ou recursos de trabalho com enfoque psicossocial para o profissional da saúde. Excluíram-se estudos relativos à unidade de terapia intensiva- UTI e que falavam de isolamento social fora do ambiente hospitalar. A figura 1 ilustra fluxograma da busca. Observa-se a significativa desproporção entre estudos que abordam aspectos psicológicos relacionados ao isolamento (quais os resultados encontrados????

Figura 1 - Fluxograma da busca em bases de dados

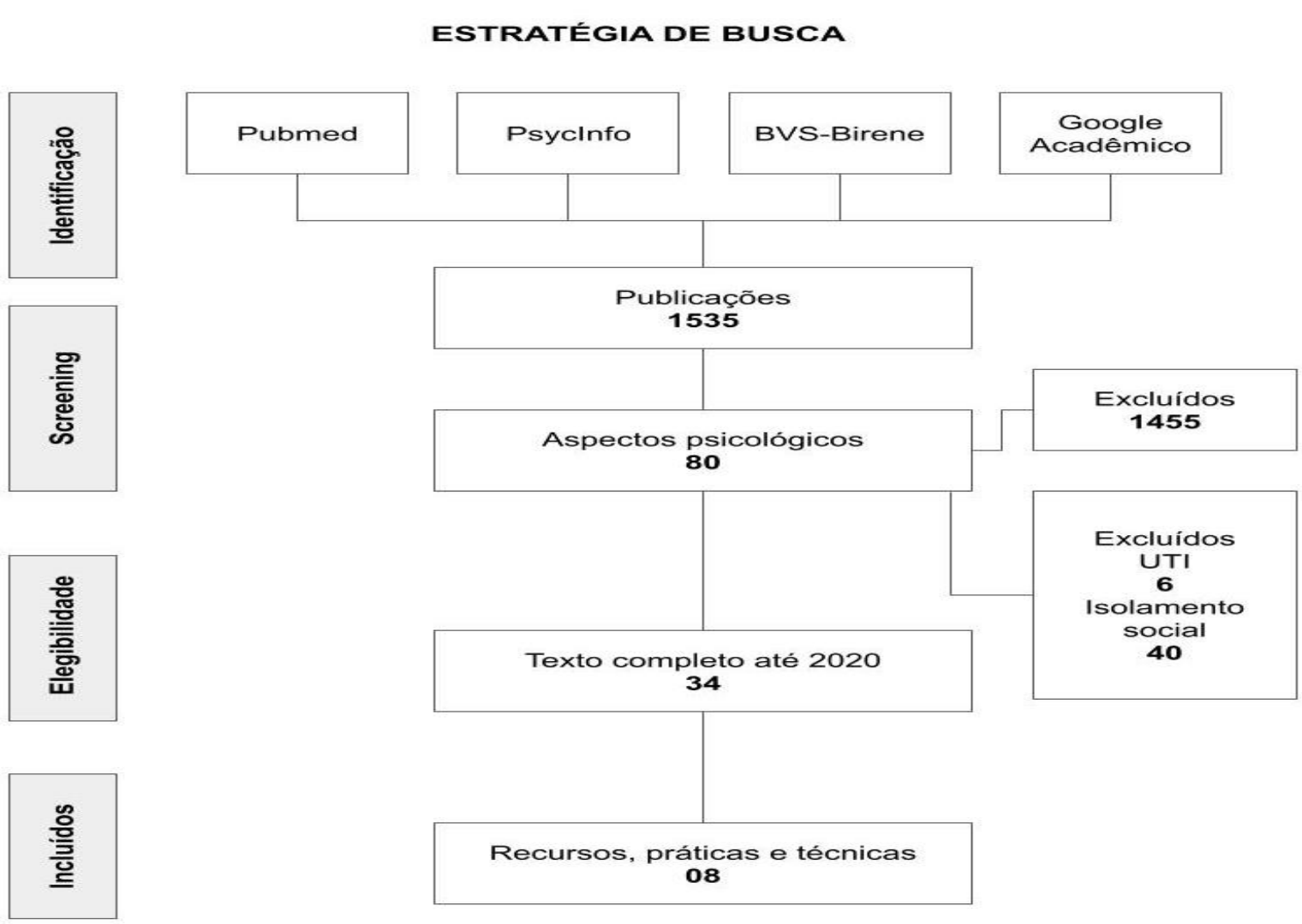

Entrevistas com psicólogos hospitalares.

Foram realizadas entrevistas abertas com três profissionais experientes atuantes em serviços pediátricos hospitalares. Eles foram indicados pelos profissionais de um hospital universitário como sendo profissionais experientes no atendimento hospitalar pediátrico. Foram 
critérios de elegibilidade: graduação em psicologia, especialização na área Hospitalar e da Saúde; no mínimo cinco anos de exercício profissional; e experiência de acompanhamento de crianças no isolamento pediátrico.

Os temas da entrevista aberta foram: a) Conte-nos sobre a sua experiência com a utilização de técnicas e práticas de humanização do atendimento no cenário específico do isolamento hospitalar pediátrico; b) quais as dificuldades na implementação dessas práticas e recursos; e c) Você tem conhecimento de outras práticas e recursos, mas que, por algum motivo, não foi possível implementar no isolamento?

\section{Busca web por recursos.}

Por fim, procedeu-se uma extensiva busca aleatória web usando os descritores: técnicas, práticas e dispositivos and humanização and isolamento hospitalar pediátrico. A busca de instrumentos atualizados foi motivada pela rápida e intensa proliferação de recursos no contexto da pandemia COVID-19, com ampla divulgação de experiências de trabalho exitosas em meios de comunicação de massa, apesar de haver pouca publicação científica sobre esses materiais.

\section{Análise dos dados.}

Foi realizada a combinação dos diferentes tipos de dados buscando convergência, divergência ou complementariedade pela triangulação. De acordo com Santos et al (2020) diz-se de dados convergentes quando os dados produzidos nas diferentes técnicas metodológicas apresentam resultados similares. Os dados são complementares quando os dados produzidos em uma técnica respondem a questões levantadas em outra técnica, complementando-a. $E$ os dados são divergentes quando as informações produzidas em uma determinada técnica são opostas às produzidas em outra. Para Nierotka, Monteiro \& Silva (2020) a triangulação é um instrumento útil que permite observar um fenômeno complexo sob diferentes perspectivas.

\section{Cuidados éticos.}

Em respeito a Resolução no 466/2012 do Conselho Nacional de Saúde esta pesquisa buscou minimizar as possibilidades de exposição e vulnerabilidade dos participantes da pesquisa. As especificações do compromisso com a ética da pesquisa estão contidas no Termo de Consentimento Livre e Esclarecido (TCLE) que foi apreciado e aprovado, bem como todo o projeto, pelo Comitê de Ética em Pesquisa da CEFAC (CAAE 46667114.6.0000.5538, parecer 1.131.595). 


\section{Resultados}

\section{Triangulação dos dados: Nível descritivo.}

\section{Pesquisa bibliográfica.}

A busca resultou no contato com aproximadamente uma centena de estudos abordando especificidades do isolamento hospitalar pediátrico. No entanto, apenas 8 artigos apresentaram claramente técnicas, recursos ou sugestões para mitigar o sofrimento psíquico gerado pelo isolamento. A tabela 1 sistematiza as informações derivadas dos cinco artigos selecionados.

Tabela 1 - Sistematização dos estudos encontrados na pesquisa bibliográfica

\begin{tabular}{|c|c|}
\hline Autores & Descrição \\
\hline $\begin{array}{l}\text { Alvarez et al. } \\
(2019)\end{array}$ & $\begin{array}{l}\text { Estudo qualitativo que destaca as } \\
\text { diferenças entre crianças e pais quanto a } \\
\text { percepções sobre o processo de } \\
\text { isolamento. Enfatiza a importância de se } \\
\text { ouvir as crianças. }\end{array}$ \\
\hline $\begin{array}{l}\text { Cardim et al. } \\
(2008)\end{array}$ & $\begin{array}{l}\text { Estudo bibliográfico/documental concluiu } \\
\text { que os clientes com enfermidades } \\
\text { infectocontagiosas em isolamento possuem } \\
\text { necessidades psicossociais que não estão } \\
\text { sendo contempladas durante o seu cuidado } \\
\text { porque existe um distanciamento entre o } \\
\text { cliente e a equipe de enfermagem, apesar } \\
\text { de ele ser permeado de afeto. }\end{array}$ \\
\hline Depianti, Melo & Estudo qualitativo mediado pelo \\
\hline $\begin{array}{l}\& \quad \text { Ribeiro } \\
(2018)\end{array}$ & $\begin{array}{l}\text { procedimento Desenho Estória com tema - } \\
\text { PDE-T realizado com seis crianças com } \\
\text { precaução de contato. }\end{array}$ \\
\hline $\begin{array}{l}\text { Ferreira et al. } \\
\text { (2019) }\end{array}$ & $\begin{array}{l}\text { Estudo teórico que investigou na base } \\
\text { científica Scielo sobre a qualidade de vida } \\
\text { de crianças no contexto da pandemia de } \\
\text { civid-19 e incluiu crianças com precaução } \\
\text { de contato. }\end{array}$ \\
\hline
\end{tabular}

- Oportunidades recreativas

- Técnicas expressivas

Recomenda o envolvimento ativo do psicólogo na proposta da brincadeira mediada por uma caixa lúdica contendo materiais de desenho, pintura, modelagem, celular de brinquedo, etc. Narra a adesão das crianças à personagens e brincadeiras, expressando-se pelo desenho, representação e brincadeiras que redundaram em simbolização e possibilidade de alívio do sofrimento psíquico.

Faz recomendações relativas a cinco categorias de análise: 1- Comunicação: maior sensibilidade para várias formas de expressão incluindo o desenho, escrita, choro; 2- Acolhimento envolvendo essencialmente a espiritualidade: 3- atenção à família possibilitando a vídeo-chamada e atenção

Rev. Psicol Saúde e Debate. Jun., 2021:7(1): 408-429. 
McClusky

Davis (2019)

Moro (2019)
\& Foca na importância de especialistas em desenvolvimento/crianças nas equipes hospitalares para adaptar vivências no isolamento, respeitada a política de prevenção de infecções hospitalares usando protocolos e solução criativa de problemas.

Foco na continuação dos processos de aprendizagem com uso de ambientes virtuais por adolescentes com fibrose cística em isolamento hospitalar. especial ao cuidador; 3- estratégias lúdicas disponibilizando materiais exclusivos de leitura e escrita, jogos e materiais descartáveis.

- Tempo privativo de uso da brinquedoteca

- Terapia assistida por animais (cachorros, cavalos e renas)

- Uso de realidade virtual para atividades físicas

- Prover doação de brinquedos, pelúcias e cobertores

\begin{abstract}
- Netmeeting para interação entre as crianças que estão no isolamento com elas mesmas e com pessoas externas

- Construção de textos interativos colaborativos por meio de páginas virtuais
\end{abstract}

Uso de photovoice, produção de imagens e narrativas a partir da produção e seleção de imagens pela própria criança

Contato constante com a mãe, o que inclui pele-apele e canguru - Investimento na amamentação. físico mãe-bebê mesmo no contexto da COVID-19. Pondera que a separação pode causar efeitos mais deletérios que a contaminação.

Os estudos selecionados foram publicados entre 2006 e 2020, sendo que a publicação de Stuebe (2020) já considera a pandemia da COVID-19. Apesar da distância temporal entre os estudos, é interessante observar que todos os artigos ressaltam a importância dos aspectos relacionais e lúdicos no trabalho com o isolamento pediátrico. A utilização de tecnologias da informação e comunicação também é relatada nos trabalhos, mas não se sobrepõem aos cuidados humanizados no isolamento pediátrico.

O trabalho de Alvarez e colaboradores (2019) é particularmente importante pois apresenta a perspectiva das próprias crianças que estão no isolamento. Os autores levantaram quatro temas principais: as dificuldades com as precauções do isolamento, dificuldades de autorreflexão, sugestões de melhoria na experiência do paciente e a dissonância entre o conhecimento dos pais versus das crianças sobre o isolamento. Eles destacam como a melhoria na comunicação com as crianças e pais poderia gerar maior conforto na situação para as famílias.

O levantamento bibliográfico também ressalta que há mais envolvidos no isolamento pediátrico além das crianças, como os pais (Alvarez et al., 2019, Stuebe, 2020), equipe de 
enfermagem (Cardim et al., 2008) e especialistas em desenvolvimento infantil (McClusky \& Davis, 2019). O cuidado multiprofissional parece fundamental para o pleno atendimento das necessidades biopsicossociais das crianças em isolamento pediátrico, e exigem dos profissionais esforços criativos e afetivos para lidar com essa adversidade.

Por fim, a publicação de Stuebe (2020) apresenta como particularidade o isolamento de bebês. Nessas situações, em que o material lúdico e atividades físicas naturalmente já não demandam grande circulação, o contato com a mãe/cuidadora principal é o ponto chave do trabalho.

\section{Entrevistas com psicólogos hospitalares.}

Foram realizadas entrevistas abertas com psicólogas atuantes em serviços de pediatria. As participantes tinham graduação em Psicologia e especialização em Psicologia Hospitalar e da Saúde, sendo que duas delas atuavam na clínica pediátrica por cinco anos e uma delas há 19 anos. Todas atuavam em hospitais públicos universitários federais e uma delas relatou experiência anterior em outro hospital público da rede estadual de saúde. Todas reportaram experiência prévia com crianças em situação de isolamento. A seguir serão destacados alguns excertos das entrevistas:

Em relação às práticas adotadas no sentido de humanizar o atendimento no isolamento hospitalar pediátrico, os recursos e práticas apontados foram:

- Permissão de manter sob a posse da criança um objeto ou brinquedo com o qual ela mantenha algum vínculo afetivo. Uma das psicólogas nomeou-o "objeto transicional", referindo-se ao aporte teórico do psicanalista Winnicott (1975);

- Escuta ativa para identificar as necessidades específicas de cada criança;

- Manutenção de um acompanhante, atribuindo essa prática a uma prerrogativa legal;

- Disponibilização de materiais escolares e práticas de contação de histórias, bem como atividades lúdicas;

- Alterações nos arranjos espaciais e nos detalhes dos EPls que podem ser amenizados com cores e "motivos" com características infantis e lúdicas;

- Manutenção de algum dispositivo eletrônico com a criança (no entanto essa é uma prática de difícil realização por orientação da $\mathrm{CCIH}$ ).

Como dificuldades na implementação de algumas práticas e técnicas, foram mencionadas:

- Falta de recursos materiais;

- Obstáculos com a $\mathrm{CCIH}$;

- Particularidades de cada caso, já que a implementação de práticas depende da gravidade do caso, da idade da criança e mesmo do nível de responsividade; 
- Abertura da equipe de saúde na flexibilização de algumas regras. De acordo com as profissionais, a equipe de enfermagem se mostra mais acessível nesse aspecto e que alguma flexibilização da equipe médica do setor também pode ser observada, mas que esse posicionamento ainda entra em colisão com as claras determinações da $\mathrm{CCIH}$.

Quanto ao conhecimento de outras práticas e recursos, foram mencionados trabalhos com pranchas de comunicação alternativa nas versões física e virtual acessadas por dispositivos eletrônicos e wi-fi no ambiente hospitalar.

\section{Buscas web por recursos.}

As buscas implementadas na web por recursos resultaram em uma infinidade de prescrições, dicas, materiais e dispositivos. Destacamos aqui os seis recursos considerados mais relevantes para a perspectiva psicológica:

- Material didático (divulgação científica) denominado "Recomendações para o cuidado de crianças em situação de isolamento hospitalar" (Melo et al., 2020). Há recomendações de permissão de acompanhantes e, na impossibilidade destes que seja viabilizado contato por meio de algum tipo de tecnologia do tipo vídeo-chamada. Se isso não for possível, os autores sugerem que alguém da equipe de saúde deve assumir o papel de referência, mantendo a rotina, a comunicação clara relativa a procedimentos, bem como a manutenção de informações que mantenham a criança orientada no tempo e no espaço.

- Contrariamente, foram encontradas recomendações da Sociedade Brasileira de Psicologia Hospitalar (2020) desencorajando a permissão de acompanhantes no contexto da COVID19. Vale ressaltar que a restrição do contato, nesse caso, leva em consideração a alta transmissibilidade do agente patógeno em questão.

- EPIs contendo fotos de profissionais sorrindo, coladas no avental ou impressas em máscaras (Araújo, 2020);

- Máscara com transparência que permite ver o sorriso e fazer leitura labial ou máscaras com motivos lúdicos (Lawrence, 2020);

- Dispositivo eletrônico robotizado para interagir e transmitir imagens no contexto de ambientes hospitalares de isolamento: Alfhabet 2.0 (Macoy, 2020).

- Brinquedo denominado Konnekt (Ribeiro, 2014) desenvolvido pelo estudante de designer Job Jansweijer. Foi desenvolvido para permitir a interação das crianças em isolamento hospitalar com outras pessoas. Através do encaixe interativo de peças no vidro é possível realizar jogos como jogo da velha, damas, xadrez, entre outros. Nesse jogo, a criança tem seu estresse amenizado e suas habilidades estimuladas. 


\section{Discussão}

A proposta de triangulação metodológica visa abordar fenômenos complexos a partir de múltiplas perspectivas. No tema em questão há que se considerar as contradições entre saberes e fazeres, prescrições técnicas e necessidades humanas, bem como apreensão do fenômeno a partir de múltiplos pontos de vista.

\section{A triangulação de dados: Nível Analítico.}

De posse dos dados levantados pela pesquisa bibliográfica, entrevistas e pesquisa via web, foram levantados os pontos de convergência e divergência ou complementariedade, conforme sugestão de Santos et al (2020).

\section{Pontos de convergência.}

O primeiro ponto de convergência observado nas três fontes de dados refere-se à importância da humanização e contato direto com os pacientes e familiares, investindo em escuta ativa e comunicação assertiva. Alvarez e colaboradores (2019) puderam apreender angústias, ansiedades e preocupações apenas oferecendo voz às próprias crianças e aos pais. Da mesma maneira, as psicólogas entrevistadas reforçaram a importância de ouvir as necessidades específicas de cada criança para que haja um acolhimento e intervenções humanizadas. Melo e colaboradores (2020) desenvolveram um material didático com recomendações que reforçam a importância dos acompanhantes e de mediadores na equipe que facilitam a comunicação clara com a criança, o acolhimento e a interação.

Um segundo ponto evidenciado nas três fontes de dados refere-se a presença do fator lúdico, seja por meio de práticas recreativas (Cardim et al., 2008; Depianti, Melo \& Ribeiro, 2018; Ferreira et al., 2019; McClusky \& Davis, 2019; Silva, 2019), contação de histórias, a manutenção de brinquedos ou objetos familiares para criança ou o próprio desenvolvimento de jogos adaptados para o isolamento hospitalar (Ribeiro, 2014).

Outro fator de convergência identificado principalmente na fala das profissionais e nos recursos dispostos na web diz respeito aos limites da flexibilização das intervenções em respeito às normas de biossegurança. Ou seja, apesar da necessária e criativa readaptação de práticas e materiais para o atendimento na clínica do isolamento, não se pode ignorar as orientações impostas 
pela CCIH que são fundamentais para a manutenção da vida e preservação da saúde dos pacientes e da equipe.

No que se refere ao fator escolar, tanto o estudo de Moro e colaboradores (2006) quanto a fala das psicólogas enfatizam a necessidade de continuidade do processo educativo formal, por meio da disponibilização de recursos e materiais didáticos.

Por fim, o uso das tecnologias como um meio facilitador e potencializador das intervenções foi ressaltado nos artigos (Moro et al., 2006; McClusky \& Davis, 2019; Silva, 2019), nas práticas das psicólogas e nos recursos web (Macoy, 2020).

\section{Pontos de divergência.}

No que se refere às divergências, os estudos de Ferreira et al (2019), McClusky e Davis (2019) propõem que a equipe de saúde, apesar de considerar as normas de biossegurança, devem atuar no sentido de adequar práticas e flexibilizar intervenções no isolamento pediátrico. Em contrapartida, as psicólogas entrevistadas ressaltam que em suas atuações a humanização das práticas estão extremamente limitadas devido à subordinação aos aspectos técnicos determinados pela $\mathrm{CCIH}$.

Ainda nestas mesmas fontes, McClusky e Davis (2019) sugerem a utilização de protocolos de intervenção uniformes desenvolvidos por especialistas da área, ideia também defendia por Stuebe (2020) nas intervenções com os bebês em isolamento. Já as profissionais das entrevistas pontuaram que sua prática de trabalho exige uma atuação personalizada, a depender da idade, quadro clínico, estrutura emocional e psicossocial de cada criança.

Outra divergência encontrada recai sobre a questão do acompanhante do paciente em isolamento. Tendo em vista o prejuízo afetivo da separação do bebê de sua mãe/cuidadora, Stuebe (2020) defende a permanência do acompanhante dos bebês, inclusive em momentos adversos, como no caso da pandemia atual. Em contrapartida, a SBPH (2020) desencoraja a permanência dos acompanhantes no atual contexto. Por fim, Melo e colaboradores (2020) reforçam a importância do acompanhante, mas ressaltam que na impossibilidade deste, deve haver um reajuste por meio de um profissional da equipe.

\section{Pontos de complementariedade.}

Como explicitado outrora, o estudo de McClusky e Davis (2019) defende que os especialistas em desenvolvimento infantil das equipes hospitalares devem desenvolver soluções criativas para os problemas identificados na experiência do isolamento pediátrico. Em complementariedade a essa questão suscitada, os recursos web identificados trazem, de modo criativo, diferentes 
possibilidades de adaptar as vivências das crianças no isolamento hospitalar, seja por meio de jogos, dispositivos eletrônicos ou EPIs diferenciados (Ribeiro, 2014; Araújo, 2020; Macoy, 2020).

Para melhor visualização dos dados triangulado, segue abaixo tabela com descrição:

Tabela 2 - Triangulação dos dados: nível descritivo

\begin{tabular}{|c|c|c|}
\hline $\begin{array}{l}\text { Ponto da } \\
\text { relação }\end{array}$ & Descrição & Fontes de Dados \\
\hline \multirow[t]{5}{*}{$\begin{array}{l}\text { Pontos de } \\
\text { convergência }\end{array}$} & $\begin{array}{l}\text { - Importância da humanização no contato } \\
\text { com os pacientes e familiares }\end{array}$ & $\begin{array}{l}\text { - Alvarez e colaboradores (2019), Psicólogas } \\
\text { entrevistadas, Melo e colaboradores (2020) }\end{array}$ \\
\hline & - Uso da ludicidade e práticas recreativas & $\begin{array}{l}\text { - Cardim et al. (2008); Depiant, Melo \& Ribeiro } \\
\text { (2018); Ferreira et al (2019); McClusky \& Davis, } \\
\text { (2019); Silva, (2019); McClusky \& Davis (2019); } \\
\text { Recursos Web, Ribeiro (2014) }\end{array}$ \\
\hline & $\begin{array}{l}\text { - Importância de se considerar as normas } \\
\text { de biossegurança }\end{array}$ & - Psicólogas entrevistadas e Recursos Web \\
\hline & $\begin{array}{l}\text { - Necessidade de continuidade da } \\
\text { educação formal }\end{array}$ & $\begin{array}{l}\text { - Moro e colaboradores (2006) e Psicólogas } \\
\text { entrevistadas }\end{array}$ \\
\hline & $\begin{array}{l}\text { - Tecnologias como facilitadoras e } \\
\text { potencializadoras das intervenções }\end{array}$ & $\begin{array}{l}\text { - Moro et al. (2006); McClusky \& Davis (2019); } \\
\text { Psicólogas entrevistadas; Recursos Web, Macoy } \\
\text { (2020) }\end{array}$ \\
\hline \multirow[t]{2}{*}{$\begin{array}{l}\text { Pontos } \\
\text { divergência }\end{array}$} & $\begin{array}{l}\text { - Possibilidades de práticas humanizadas } X \\
\text { Práticas humanizadas impossibilitadas pelo } \\
\text { rigor das normas de biossegurança }\end{array}$ & $\begin{array}{l}\text { - Ferreira et al (2019); McClusky e Davis (2019); } \\
\text { Psicólogas entrevistadas }\end{array}$ \\
\hline & $\begin{array}{l}\text { - Protocolos de intervenção uniformizados } \\
X \text { Intervenções personalizadas } \\
\text { - Permanência do acompanhante junto ao } \\
\text { paciente em isolamento X Desencorajar a } \\
\text { presença dos acompanhantes }\end{array}$ & $\begin{array}{l}\text { - McClusky e Davis (2019); Stuebe (2020); } \\
\text { Psicólogas entrevistadas } \\
\text { - Stuebe (2020); SBPH (2020) }\end{array}$ \\
\hline $\begin{array}{l}\text { Pontos de } \\
\text { complementarid } \\
\text { ade }\end{array}$ & $\begin{array}{l}\text { - Necessidade de especialistas em } \\
\text { desenvolvimento infantil desenvolverem } \\
\text { soluções criativas. }\end{array}$ & $\begin{array}{l}\text { - McClusky e Davis (2019); Recursos Web; Ribeiro } \\
\text { (2014); Araújo (2020); Macoy (2020) }\end{array}$ \\
\hline
\end{tabular}

\section{Reflexões sobre as práticas e recursos no isolamento.}

Realizado o esforço teórico na tentativa de estabelecer a triangulação metodológica cumpre recuperar o objetivo desse trabalho que buscou acessar as práticas e recursos utilizados em Rev. Psicol Saúde e Debate. Jun., 2021:7(1): 408-429. 
ambientes de Isolamento Hospitalar Pediátrico com vistas diminuir o sofrimento psíquico provocado duplamente pela condição da doença e do afastamento social. Como essa circunstância pode trazer graves consequências emocionais para as crianças, conforme amplamente discutido na literatura desde as clássicas publicações de Spitz (1991) e Bowby (1979/1997), o psicólogo hospitalar especialmente, bem como toda a equipe de saúde não deve poupar esforços para oferecer a melhor experiência possível no isolamento hospitalar pediátrico.

A manutenção ou não do contato com o acompanhante emergiu como um tema de divergência na triangulação dos dados. Melo et al. (2020) destacaram a prerrogativa legal do acompanhante e Stuebe (2020) defendeu veementemente a permanência e o contato físico mãebebê mesmo na pandemia de COVID19, como fator protetor. Por outro lado, a Sociedade Brasileira de Psicologia Hospitalar (2020) recomenda que se evite o acompanhante neste mesmo contexto (de alta transmissibilidade do agente patógeno). Há que se destacar que frente a esse impasse parece haver uma via de resolução conciliatória. É claro que, como pontuado nas entrevistas, as recomendações da $\mathrm{CCIH}$ devem ser respeitadas para manutenção da vida da criança e do bemestar coletivo, mas esses protocolos, sempre que possível, devem levar em consideração os princípios de benevolência relativos também ao que dia respeito à saúde mental, da mesma forma que se pode melhorar o conhecimento e as condições de biossegurança do acompanhante.

Vale a pena reforçar, ainda que a clínica do isolamento possui limitações quanto aos procedimentos técnicos e suporte à vida, mas que é necessário uma constante negociação e ponderação com a equipe sobre os riscos/benefícios de adoção de práticas de humanização do atendimento. A manutenção da saúde mental não deve ser rebaixada em nome do bem-estar físico, mas deve ser também um dos objetivos do trabalho de toda equipe de saúde.

É absolutamente legítimo e desejável que, conhecendo os princípios de biossegurança (Carvalho \& Marques, 1999; Nichiata et al., 2004; Brasil, 2006; Yamamura et al., 2011; OMS, 2016; Melo et al., 2020), toda a equipe se responsabilize por ela e, igualmente, ofereça um atendimento digno e humanizado. Não se trata de uma subordinação hierárquica do saber técnico sobre o ético, mas a defesa de que não é ético não ter uma técnica, nem é tecnicamente correto não ser ético.

O dado levantado pelas profissionais acerca da falta de EPIs também é uma realidade em nosso país e é central no estabelecimento do cuidado humanizado. E aí não se trata apenas de se obter permissão para o acompanhante, mas garantir que o cuidado oferecido aconteça dentro dos princípios de segurança. Orientação e psicoeducação sobre as precauções para os cuidadores poderia minimizar os riscos para ambos, mas temos que considerar a manutenção de pelo menos um objeto de apego como sugerido nas entrevistas.

Ainda sobre a presença de uma figura de vinculação da criança e a presença do acompanhante, observamos a disseminação da ideia do uso de tecnologias da informação e comunicação (TICs) para manutenção do contato com familiares. Este tema foi convergente na 
triangulação de dados e pode ser sim um excelente mediador do contato. No entanto, é importante destacar que do ponto de vista psicológico as TICs não são capazes de substituir as relações presenciais. O contato humano exigido por uma criança extrapola as possibilidades que as TICs podem oferecer, já que envolvem afeto, aconchego, cheiros, comunicações não-verbais, entre outros. Assim, concordando que as TICs são uma alternativa de qualidade para manutenção do contato com familiares, elas não são capazes de esgotar a necessidade afetiva das crianças por um acompanhante.

As TICs parecem oferecer oportunidades incríveis para alguns fins, como o educacional e contato com outras crianças. Moro e colaboradores (2006) e Silva (2020) propõem netmeetings entre as crianças que estão no isolamento, o que pode ser muito interessante para identificação, compartilhamento e acolhimento da situação que todos estão vivendo. Além disso, os autores sugerem jogos eletrônicos com realidade virtual para a realização de atividades físicas com aquelas crianças que possam se locomover dentro do quarto de isolamento. Destaca-se aqui que a defesa das TICs envolve os meios e não constituem um fim em si mesmo. A humanização do atendimento deve se apoiar, prioritariamente, na dimensão do encontro genuíno entre dois seres humanos. A técnica e os recursos materiais são mediadores e não atores da situação.

Reforça-se que o princípio de humanização ultrapassa em muito a mera oferta de recursos materiais. Diz respeito antes de tudo, a necessidade inerente ao ser humano de contato, como bem demonstraram os estudos de Spitz (1945), Bolwby (1985/2004); Parcianello e Felin, (2008), Depianti, Melo e Ribeiro (2018) e Ferreira et al (2020) e à sensibilidade de se identificar dimensões do sofrimento psíquico presentes em cada situação. $O$ uso de recursos deve estar sempre disponível, mas não se constitui como fundante.

Não se trata de dispensar toda ordem de materiais, pelo contrário, defende-se a franca disponibilização de toda a gama de recursos aqui elencados. No entanto, que a decisão de os utilizar não passe apenas pelo crivo da disponibilidade e do instrumentalismo, mas pelo olhar e avaliação atenta e sensível da equipe de saúde.

Além disso, discute-se que a adoção desses procedimentos depende de fatores relacionados à letalidade do agente patógeno, à idade e o interesse da criança, o nível de responsividade do paciente, do acesso a recursos materiais e a flexibilidade da equipe de saúde em ponderar sobre riscos/benefícios, ensejando práticas idiossincráticas.

\section{CONSIDERAÇÕES FINAIS}

Observou-se um interesse crescente no tema do isolamento, e mesmo circunstancial, relacionado ao momento atual da pandemia COVID-19. Esse fato internacional ensejou a busca por sistematização de condutas nesse contexto e alguns recursos encontram evidências de eficácia no 
cotidiano e na relação direta da equipe com seus condicionantes circunstanciais. No entanto, o uso desses recursos deve ser estudado pela ciência para fornecer aporte técnico e teórico aos profissionais de saúde.

Frente às necessárias problematizações e produção de conhecimento, enfatiza-se que jamais haverá receitas aplicáveis a todas as situações. Defende-se aqui a busca incessante por evidências científicas que embasem nossas ações, mas que não se perca em nenhum momento o aspecto da singularidade que marca cada interação humana, independente do contexto, mormente, numa situação limite de ameaça à vida. Todavia, cada reflexão, compartilhamento e pesquisa servem como parâmetros para outras atuações e estudos. Aquilo que desafia é justamente o que enriquece cada pesquisa e move a continuidade deste processo: a imprevisibilidade da subjetividade.

O sentido é sempre uma produção singular, conforme Mori e Rey (2012), de modo que nenhum processo de adoecimento e internação será portador de sentido subjetivo em si mesmo. profissional terá sempre o instigante desafio de, considerando o plano de fundo de seus estudos, acessar com curiosidade a singular experiência de cada criança. Assim, o acesso a este universo simbólico implica, sobretudo, o entendimento do contexto de vida e a configuração subjetiva particular do sujeito. E é neste processo que emerge a importância de intervenções que organizam o sentido e significado da experiência singular da criança, extraindo crescimento em meio à dor.

Vale a pena reforçar, ainda, que a clínica do isolamento possui limitações quanto aos procedimentos técnicos e suporte à vida, mas que é necessário uma constante negociação e ponderação com a equipe sobre os riscos/benefícios de adoção de práticas de humanização do atendimento. A manutenção da saúde mental não deve ser rebaixada em nome do bem-estar físico, mas deve ser também um dos objetivos do trabalho de toda equipe de saúde.

Estudos futuros deverão sistematizar as ações produzidas durante o curso da pandemia COVID19 e sua validação passa necessariamente pelo crivo do diálogo entre a ciência biomédica e psicológica e pela idiossincrasia que caracteriza toda e qualquer relação humana. 


\section{REFERÊNCIAS}

Abad, C., Fearday, A., \& Safdar, N. (2010). Adverse effects of isolation in hospitalized patients: a systematic review. Journal of Hospital Infection, 76(2), 97-102.

Alvarez, E. N., Pike, M. C., \& Godwin, H. (2019). Children's and parents' views on hospital contact isolation: A qualitative study to highlight children's perspectives. Clinical Child Psychology and Psychiatry, 25(2), 401-418.

Araújo, G. (2020). Equipe do hospital adapta crachás com foto na roupa de proteção para não assustar pacientes de coronavírus no ABC paulista. Recuperado em 28/04/2020, de https://g1.globo.com/sp/sao-paulo/noticia/2020/04/21/equipe-de-hospital-adaptam-crachascom-foto-na-roupa-de-protecao-para-nao-assustar-pacientes-de-coronavirus-no-abcpaulista.ghtml

Bowlby, J. (1997). Formação e rompimento dos laços afetivos (3a ed.). São Paulo: Martins Fontes. (Trabalho original publicado em 1979)

Bowlby, J. (2004). Apego e perda. Perda: tristeza e depressão (Valtensir Dutra, Trad.). São Paulo: Martins Fontes. (Original publicado em 1985)

Brasil. (2006). Ministério da Saúde. Agência Nacional de Vigilância Sanitária. Pediatria: Prevenção e controle de infecção hospitalar. [Versão eletrônica]. Brasília: ANVISA.

Cardim, G. M., Santos, A. E. V., Nascimento, M. A. L., \& Biescroeck, F. C. C. (2008). Crianças em isolamento hospitalar: relações e vivências com a equipe de enfermagem. Revista de Enfermagem UERJ, 16(1), 32-38

Carvalho, E. S. \& Marques, S. R. (1999). Infecção Hospitalar em Pediatria. Jornal de Pediatria,75(1), 31-45.

Chiattone, H. B. C (2009). A criança e a hospitalização. In: Angerami-Camon, V. A., Chiattone, H. B. C., \& Meleti, M. R. (Orgs.). A Psicologia no hospital (2a ed.). São Paulo: Cengage Learning, 23-99.

Committee on Infectious Diseases, American Academy of Pediatrics, David,W.,Kimberlin, M.D., Brady, M. T., Jackson, M. A., \& Long, S. S.(2018). Red Book. Recuperado em 22/04/2020, de https://redbook.solutions.aap.org/book.aspx?bookid=2205.

Depianti, J. R. B., Melo, L.L., \& Ribeiro, C. A. (2018). Brincando para continuar a ser criança e libertar-se do confinamento da hospitalização em precaução. Escola Anna Nery, 22(2), 1-9.

Ferreira, E. A. L., Menegussi, J. M., Bombrada, T. B., Torcia, V. C., Silva, I. D., \& Piovesan, S. (2020). Qualidade de vida da criança hospitalizada na pandemia de COVID-19. Residência Pediátrica, 10(3), 1-13.

Lawrence, A. (2020). Coronavírus: estudante cria máscara transparente para ajudar na leitura labial de surdos. Tudo celular. Recuperado em 20/04/2020 de https://www.tudocelular.com/tech/noticias/n154984/coronavirus-estudante-cria-mascaratransparente.html. 
Macoy, J. (2020).Association of child life professionals. Alphabet 2.0 / T is for Telepresence: Utilizing Technology to Increase Socialization and Interactive Engagement Among Pediatric Patients on Isolation Precautions. Recuperado em 27/04/2020, de https://www.childlife.org/membership/aclp-bulletin/winter-2020-table-of-contents/alphabet-2.0t-is-for-telepresence-utilizing-technology

McNeil, J.C., Campbell, J.R., \& Crews, J.D. (2019) Healthcare-Associated Infections in Children A Guide to Prevention and Management. San Antonio, Texas.Recuperado em 19/04/2020 de https:// doi.org/10.1007/978-3-319-98122-2

McClusky, J. L.\& Davis, M. (2019). A Horse in the Hospital: The Importance of Collaboration between Infection Prevention and Child Life Specialists. American Journal of Infection Control, 47(6).

Melendo, L. M.,Vilca, I.,Albero, N.,Larrosa, M., De Arquer, A., \&Campins, M. (2011). Precauciones de aislamientoen un hospital pediátrico de tercernivel. Anales de Pediatria, 75(1), 21-25.

Melo, B.D., Angelucci, C.B., Pereira, D.R., Serpeloni, F., Katz, I., Rodrigues, I., Rabelo, I. V. M.,Kabad, J.F., Souza,M. S., \&Sibemberg, N. (2020). Recomendações para o cuidado de crianças em situação de isolamento hospitalar. Brasília: Fiocruz. Recuperado em 18/04/2020, dehttps://www.fiocruzbrasilia.fiocruz.br/cartilhas-reunem-informacoes-e-recomendacoes-emsaude-mental-na-pandemia-de-covid-

19/?fbclid=IwAR0iSZ9fKpnBMk7PhC3GT1DSfUTztrDH0IzGwWYqcx1vYJ9gM_vz2Z4D7IA

Miranda, E. M. F. (2019). Reflexões sobre a participação do psicólogo hospitalar no controle das infecções relacionadas à assistência à saúde. In Angerami,V. A. (2019). A Psicologia da Saúde na Prática. Belo Horizonte: Artesã.

Mori, V. D. \& Rey, F. G. (2012). A saúde como processo subjetivo: uma reflexão necessária. Psicologia: teoria e prática. 14(3),140-152.

Moro, E. L. S. (2019). O processo de aprendizagem e de interação em ambientes virtuais de aprendizagem com adolescentes com fibrose cística em isolamento hospitalar. Porto Alegre, PPGEDU/UFRGS.

Nichiata, L. Y. I., Gir, E., Takahashi, R. F., \& Ciosal, S. I. (2004). Evolução dos isolamentos em doenças transmissíveis: os saberes na prática contemporânea. Revista da Escola de Enfermagem da USP, 38(1), 61-70.

Nierotka, R.P., Monteiro, A. M., Silva, M. E.K. (2020). Triangulação na pesquisa em saúde: princípios, possibilidades e desafios. Anais do 6ํㅜ congresso Internacional de Saúde.

Parcianello, A. T. \&Felin, R. B. (2008). E agora doutor, onde vou brincar? Considerações sobre a hospitalização infantil. Barbarói, 28, 147-166.

Rowold, K. (2018). What Do Babies Need to Thrive? Changing Interpretations of "Hospitalism" in an International Context. Social History of Medicine, 32(4), 799-818.

Rabelo, A. H. S. \& Souza, T. V. (2009). O conhecimento do familiar/acompanhante acerca da precaução de contato: contribuições para a enfermagem pediátrica. Escola Anna Nery,13(2), 271-278.

Ribeiro, M. (2014). Um jogo que ajuda crianças em isolamento hospitalar a brincar umas com as outras. Razões para acreditar. Recuperado em 21/04/2020, de 
http://razoesparaacreditar.com/criar/um-jogo-que-ajuda-criancas-em-isolamento-hospitalar-abrincar-umas-com-as-outras/.

Santos, K. S., Ribeiro, M. C., Queiroga, D. E. U., Silva, I. A. P., \& Ferreira, S.M.S. (2020). O uso de triangulação múltipla como estratégia de validação em um estudo qualitativo. Ciência \& Saúde Coletiva, 25(2), 655-664.

Silva, J. I. P., Kudo, A.M., Galheigo, S. M., Jacob, L. R. Isolamento hospitalar pediátrico: o olhar da criança. (2019). RevisbraTO, 3(4), 508-525.

Sociedade Brasileira de Psicologia Hospitalar(2020). Recomendações aos Psicólogos Hospitalares frente à Pandemia do Covid-19.Retirado de https://www.facebook.com/permalink.php?story_fbid=1314230778774450\&id=1590868842888 $51 \& \_\mathrm{tn} \_=\mathrm{K}-\mathrm{R}$

Spitz. R. A. (1945) Hospitalism, The Psychoanalytic Study of the Child, 1:1,53-74.

Spitz, R. (1991). O primeiro ano de vida: um estudo psicanalítico do desenvolvimento normal e anômalo das relações objetais - 6 ed. São Paulo: Martins Fontes.

Stuebe, A. (2020). Should Infants Be Separated from Mothers with COVID-19? First, Do No Harm. Breasfeeding Medicine. Ahead of print.

Winnicott, D. W. (1975). O Brincar \& a Realidade. Rio de Janeiro: Imago Editora.

World Health Organization (2016). Health care without avoidable infectionsThe critical role of infection prevention and control. Pocket Book of Hospital Care for Children: Guidelines for the Management of Common Childhood Illnesses. 2nd edition. Geneva: World Health Organization.

Yamamura, M., Dias, A. A. L., Milani, D., Santos, E. C., Dornelas, J., \& Figueiredo, R. M. (2011) Produção nacional e acesso sobre enfermagem e doenças transmissíveis. Cient. Cien. Biol. Saúde, 13(1), 299-306. 